Journal of Engineering and Applied Sciences 14 (3): 684-692, 2019

ISSN: 1816-949X

(C) Medwell Journals, 2019

\title{
Model Simulation of Cs-137 Contaminate at Al-Tuwaitha Site
}

\author{
Ahmed Hazim Abdulkareem, Ayad Sleibi Mustafa and Rasha Ali Soud \\ Department of Civil Engineering, College of Engineering, University of Anbar, Ramadi, Anbar, Iraq
}

\begin{abstract}
This study simulate the transfer of Cs-137 contaminate of the aquifer system for Nuclear Research Center at Al-Tuwaitha site, using processing MODFLOW Software package Version 8 . The site is located in South of the province of Baghdad near the Tigris River and contaminated with radiation as a result of exposure for bombing and acts of vandalism and looting in 2003. MT3D Model was used to study the contaminant distribution in aquifer and its change with time. The results of transport model showed that the spread of Cs-137 contaminate increased with time and its direction with the ground water movement. The migration of contaminants in horizontal direction is low which the seepage velocity for the first, second and third layer were $0.0357,0.51$ and $1.76 \mathrm{~m} /$ year, respectively with approximately oval shape based on the ratio of longitudinal dispersion and diffusion coefficients. A distance of $690 \mathrm{~m}$ that the plume moved during 20 years of the simulation towards the pumping well existing in the direction of the water of the Tigris River. It was a relationship between the surface water (Tigris River), groundwater and the nature of the soil, a change in one of those elements may affect the others.
\end{abstract}

Key words: Simulation Model, Cs-137, MT3D, groundwater contamination, Tigris River, transport model

\section{INTRODUCTION}

Groundwater is a renewable resource which (if managed correctly) ensures supply of water for the long term decreases the impacts of anticipated climate changes. Groundwater is closely interrelated to other components of the environment (Guzha, 2008). However, many of the materials may contaminate groundwater and leave it unfit for consumption by pollutants seeping through the soil, either directly or indirectly via. surface water. Contaminants that can dissolve in groundwater will move along with the water and pollute very large volumes and areas of groundwater. Contamination may cause degradation in water quality and can create hazards to public health through toxicity or spread of disease. The most dangerous pollutants in groundwater are radioactive and heavy materials. Radiological pollution may result from the dissolving of the components aquifer or as a result of nuclear explosions where the soil absorbs the radiation that will be seeping into the groundwater (Pepper et al., 2011). Radioactive contaminants cause a significant risk for health that could impact future generations including cancers and birth defects and this is what presumably happened in Iraq (Rasheed, 2013).

The environment of Iraq was exposed to radioactive uranium pollution as a result of wars, particularly the 2003 war. Nuclear Research Center at Al-Tuwaitha was exposed to a bombing, looting and vandalism later, leading to the leakage of radioactive materials. Containers carrying signs of radioactivity and a number of radioactive traces were found in farms, villages and the houses surrounding areas at Al-Tuwaitha, South of Baghdad (Rasheed, 2013).

Cs-137 is a radioisotope and chemically unstable which is created as one of the popular fission outputs by the nuclear fission of U-235 and other fissionable isotopes in nuclear reactors, nuclear weapons and product of the nuclear fission of much heavier elements as in the Goiania accident of 1987 the Acerinox accident of 1998 (LaForge, 1999) and in 2003 in Iraq. Cs-137 has a half-life of about 30.17 years (Unterweger et al., 1992) and isotope mass is $136.907 \mathrm{~g}$ where $1 \mathrm{~g}$ of Cs-137 has an activity of $3.215 \mathrm{TBq}$. Principle rays emissions of Cs-137 are Beta, Gamma (g)/X-Rays, Alpha $(\alpha)$ and Neutron (n).

It causes observable effects on health on a long-term including increased cancer risk depending on the route, magnitude and duration of exposure. It considers one of the contaminants of main worries due to their ease of entry into biological systems. The exposure to amounts of Cs-137 can lead acute radiation sickness and cancer (LaForge, 1999). Cs-137 is an isotope that attracts the attention of many researchers and scholars all over the world due to its chemical nature. Some of these studies are related to the transport of $\mathrm{Cs}-137$ in soils and groundwater.

Corresponding Author: Ahmed Hazim Abdulkareem, Department of Civil Engineering, College of Engineering, University of Anbar, Ramadi, Anbar, Iraq 
Tried a number of scientists and researchers to study the groundwater pollution problems. The migration characteristics of Cs-137 in the packed column was studied by Lee et al. (1990) and they compared the results with two mathematical models, the bulk reaction model and mass transfer model. The results obtained from the comparison showed that the mass transfer model with the assumption of intraparticle diffusion simulated the migration behavior of Cs-137 more adequately. They found hydrodynamic dispersion coefficient was 0.0011 $\mathrm{cm}^{2} / \mathrm{g}$ and distribution coefficient was $11.3 \mathrm{cc} / \mathrm{g}$. Bucur et al. (2000) estimated the parameters that control migration of radio-nuclides (Cs-137) in geological medium and groundwater. It was found that the diffusion coefficient for $\mathrm{Cs}-137$ in the clay soil was greater than loess soils, about $9.89 \times 10^{-6} \mathrm{~cm}^{2} / \mathrm{sec}$, also, the distribution coefficient was $120 \mathrm{~mL} / \mathrm{g}$. This is because the clay content affects the absorption of the radioactive material. Dmitri (2014) assessed groundwater contamination with radioactive materials including Cs-137 as a result of Chernobyl accident. It was found that a high concentration of $\mathrm{Cs}$ as a result of the leak and showed that the movement of $\mathrm{Cs}-137$ in soil and groundwater was slowly and absorption coefficient of $100-700 \mathrm{~L} / \mathrm{kg}$. The radiological risk which resulted from destruction of nuclear reactor in Al-Tuwaitha area, Iraq was estimated by Al Obaidy et al. (2013). They found that the concentration levels of uranium series, Sr-90,
Cs-137 and cobalt 60 were higher than the environmental levels through analyzing collection of soil samples. Zaboon et al. (2014) evaluated Cs-137 levels in Al-Tuwaitha nuclear site by using a GIS technique. They showed that the distribution of $\mathrm{Cs}-137$ in soil samples was variable about $77 \mathrm{~Bq} / \mathrm{g}$ and higher than the levels of normal environment. The transport Cs-137 in loam clay soils leached with the convection-dispersion model was investigated and assessed by Shihab (2014). It was found that the distribution coefficient for $\mathrm{Cs}-137$ was $20-295 \mathrm{~mL} / \mathrm{g}$ and retardation factor was 821 and 118 while the dispersion coefficient was 2 and 2.8 .

\section{MATERIALS AND METHODS}

Site description: The Nuclear Research Center is located at Al-Tuwaitha site about $18 \mathrm{~km}$ South of the Southern edge of Baghdad governorate between (442 $27^{\prime}-44^{\circ} 35^{\prime}$ ) longitude and $\left(33^{\circ} 10^{\prime}-33^{\circ} 15^{\prime}\right)$ latitude and covers about $10^{2} \mathrm{~km}^{2}$ as shown in Fig. 1. It is located South of the confluence point of the River Tigris and Diyala. Estimated distance of Al-Tuwaitha is around $1 \mathrm{~km}$ east of the Tigris River and $3.5 \mathrm{~km}$ South of the Diyala River.

Al-Tuwaitha is located in lower Mesopotamian plain that is covered with Quaternary-age alluvial deposits that are as much as $50 \mathrm{~m}$ thick. The deposits are composed of alternating layers of clay, silt, sand and occasional gravel. It is characterized by a flat floor surface, surrounded by

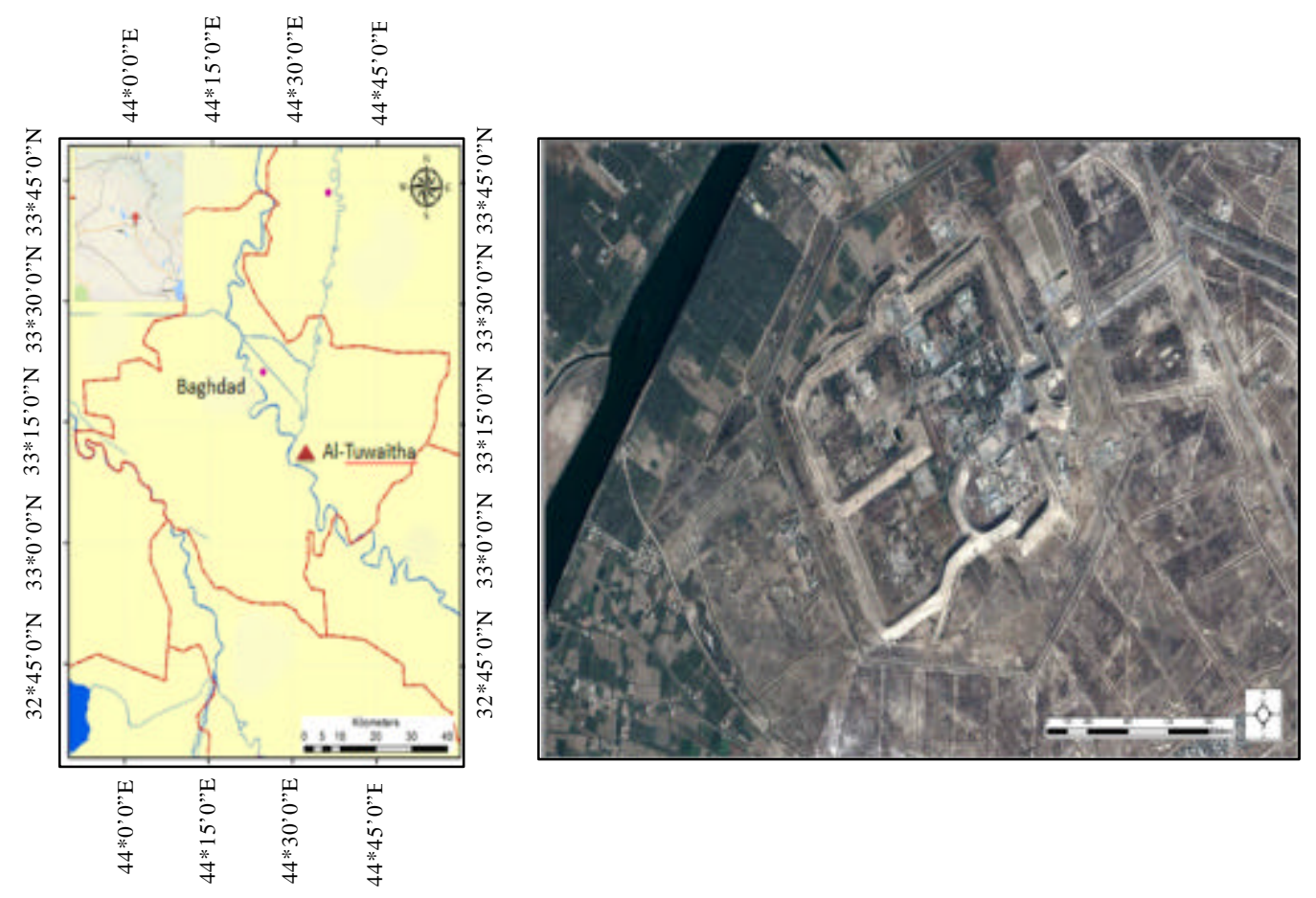

Fig. 1: Location of Nuclear Research Center at Al-Tuwaitha site (Al-Daffaie, 2014) 
earthen dikes and ranging from $30-32 \mathrm{~m}$ above mean sea level and the topography factor has no significant impact on water level and groundwater movement (Copland and Cochran, 2013).

Groundwater model: Three models for solving the mathematical models numerically were used by using the finite difference method with processing MODFLOW interface. The first and second models (MODFLOW and PMPATH) have been implemented in the solution of groundwater movement problems. While the third model MT3D was applied for the determination of contaminant transporting movement and distribution, it communicates with MODFLOW Model through data files. This should link known ground water movement to determine the distribution and movement of a contaminant in groundwater.

The process of groundwater flow is based on Darcy's law and the conservation of mass which describes the three dimensional movement of groundwater flow of constant density through the porous media by Rushton (2004).

$$
\frac{\partial}{\partial \mathrm{x}}\left(\mathrm{k}_{\mathrm{z}} \frac{\partial \mathrm{h}}{\partial \mathrm{x}}\right)+\frac{\partial}{\partial \mathrm{y}}\left(\mathrm{k}_{\mathrm{y}} \frac{\partial \mathrm{h}}{\partial \mathrm{y}}\right)+\frac{\partial}{\partial \mathrm{z}}\left(\mathrm{k}_{\mathrm{z}} \frac{\partial \mathrm{h}}{\partial \mathrm{z}}\right)=\mathrm{S}_{\mathrm{s}} \frac{\partial \mathrm{h}}{\partial \mathrm{t}}-\mathrm{W}
$$

Where:

$$
\begin{array}{ll}
\mathrm{k}_{\mathrm{z}}, \mathrm{k}_{\mathrm{y}}, \mathrm{k}_{\mathrm{z}}= & \begin{array}{l}
\text { Components of the hydraulic conductivity } \\
\text { tensor }\left[\mathrm{LT}^{-1}\right]
\end{array} \\
\mathrm{S}_{\mathrm{s}}= & \text { The Specific Storage }[\mathrm{L}] \\
\mathrm{h} & =\text { The ground water head }[\mathrm{L}] \\
\mathrm{x}, \mathrm{y}, \mathrm{z}= & \text { Cartesian coordinates directions }[\mathrm{L}] \\
\mathrm{t} & =\text { Time }[\mathrm{T}]
\end{array}
$$

$\mathrm{W}(\mathrm{x}, \mathrm{y}, \mathrm{z}, \mathrm{t})$ the rate of ground water discharge/ recharge per unit area $\left[\mathrm{LT}^{-1}\right]$, general sink/source term that is intrinsically positive and defines the volume of inflow to the system per unit volume of aquifer per unit of time $\left[\mathrm{T}^{-1}\right]$. The groundwater flow ran in steady-state where the term $\mathrm{S}_{\mathrm{s}} \partial \mathrm{h} / \partial \mathrm{t}$ equal to zero. While the partial differential equation describing three-dimensional transport of contaminants in groundwater can be written as follows:

$$
\frac{\partial C}{\partial t}=\frac{\partial}{\partial x_{i}}\left(D_{i j} \frac{\partial C}{\partial x_{j}}\right)-\frac{\partial}{\partial x_{i}}\left(V_{i} C\right)+\frac{q_{x}}{n} C_{S}+\sum_{k-1}^{N} R_{c}
$$

Where:

$\mathrm{C}=$ The concentration of contaminant dissolved in groundwater

$\mathrm{t}=\mathrm{A}$ time $(\mathrm{t})$
Table 1: Water elevation of observation wells (Copland and Cochran, 2013) Observed well Ground surface elevation (m) Water table (m.a.s.l)

\begin{tabular}{lll}
\hline W1 & 31.81 & 27.79 \\
W2 & 31.57 & 27.86 \\
W3 & 32.02 & 27.80 \\
W4 & 31.56 & 27.61 \\
W5 & 31.14 & 27.14 \\
W6 & 31.88 & 27.67 \\
\hline
\end{tabular}

$\mathrm{x}_{\mathrm{i}}=$ The distance along the respective Cartesian co-ordinate axis

$D_{i j}=$ The hydrodynamic Dispersion coefficient

$v_{i}=$ The seepage or linear pore water velocity

$\mathrm{q}_{s}=$ The volumetric flux of water per unit volume of aquifer representing sources (positive) and sinks (negative)

$\mathrm{C}_{\mathrm{s}}=$ The Concentration of the sources or the sinks

$\mathrm{n}=$ The porosity of the porous medium

$\mathrm{R}_{\mathrm{k}}=\mathrm{A}$ chemical Reaction term

The transport model ran with advection and dispersion factors.

Data collection: Water level data for six observation wells located at Al-Twaitha area were put for groundwater modeling as in Table 1 . The recharge is applied to top grid layer and the input parameter is assumed to be constant during the time stress period and the principal source for it is the rainfall. The value of recharge rate was $2 \times 10^{-5}$ $\mathrm{m} /$ day. The pumping well was suggested in this research for treatment. It is used to reduce or limit spreading of contamination in the aquifer and the recharge rate of this well was about $518 \mathrm{~m}^{3} /$ day. One site in the study area is regarded as possible contaminant with $\mathrm{Cs}-137$ that applied in this with value of $76.9 \mathrm{~Bq} / \mathrm{g}$ (Zaboon et al., 2014). The longitudinal dispersivity is taken as $3 \mathrm{~m}$ (Ali, 2012) and standard ratios transverse to longitudinal dispersivity equal 0.1 (Gelhar, 1986). Aquifer properties such as hydraulic conductivity, effective porosity and diffusion coefficient for each layer were given as input to the model as in Table 2.

Model discretization: The model consists of 28 rows and 57 columns in each layer as in Fig. 2 with cell size $80 \times 80 \mathrm{~m}$. Based on the acquired information the model has been divided into three layers, top layer has loam clay sand with a thickness of $16 \mathrm{~m}$ approximately, the middle layer is $14 \mathrm{~m}$ thick silt fine sand and bottom layer is made up of predominantly medium sand with a thickness of $20 \mathrm{~m}$. MODFLOW is used to estimate the distribution of hydraulic heads in steady-state and PMPATH is used to calculate the ground water flow paths while (MT3D) is used to estimate the distribution Cs-137 which vary with time. 
Table 2: The aquifer properties

\begin{tabular}{|c|c|c|c|c|}
\hline Soil type & Layer type & Hydraulic conductivity ( $\mathrm{m} /$ day) & Effective porosity & Molecular diffusion $\left(\mathrm{m}^{2} / \mathrm{sec}\right)$ \\
\hline Loam/Clay & Unconfined & $0.001-0.09$ & $0.01-0.18$ & $1 \times 10^{9}$ \\
\hline Silt /Fine sand & $\begin{array}{l}\text { Confined/unconfined, } \\
\text { transmissivity varies }\end{array}$ & $0.09-0.9$ & $0.20-0.33$ & $1 \times 10^{8}$ \\
\hline Medium sand & $\begin{array}{l}\text { Confined/unconfined, } \\
\text { transmissivity varies }\end{array}$ & $1-12$ & $0.16-0.46$ & $5 \times 10^{8}$ \\
\hline
\end{tabular}

Al-Daffaie (2014), Ali (2012), Wiedemeier et al. (1999), Chiang and Kinzelbach (1998) and Lee et al. (1990)

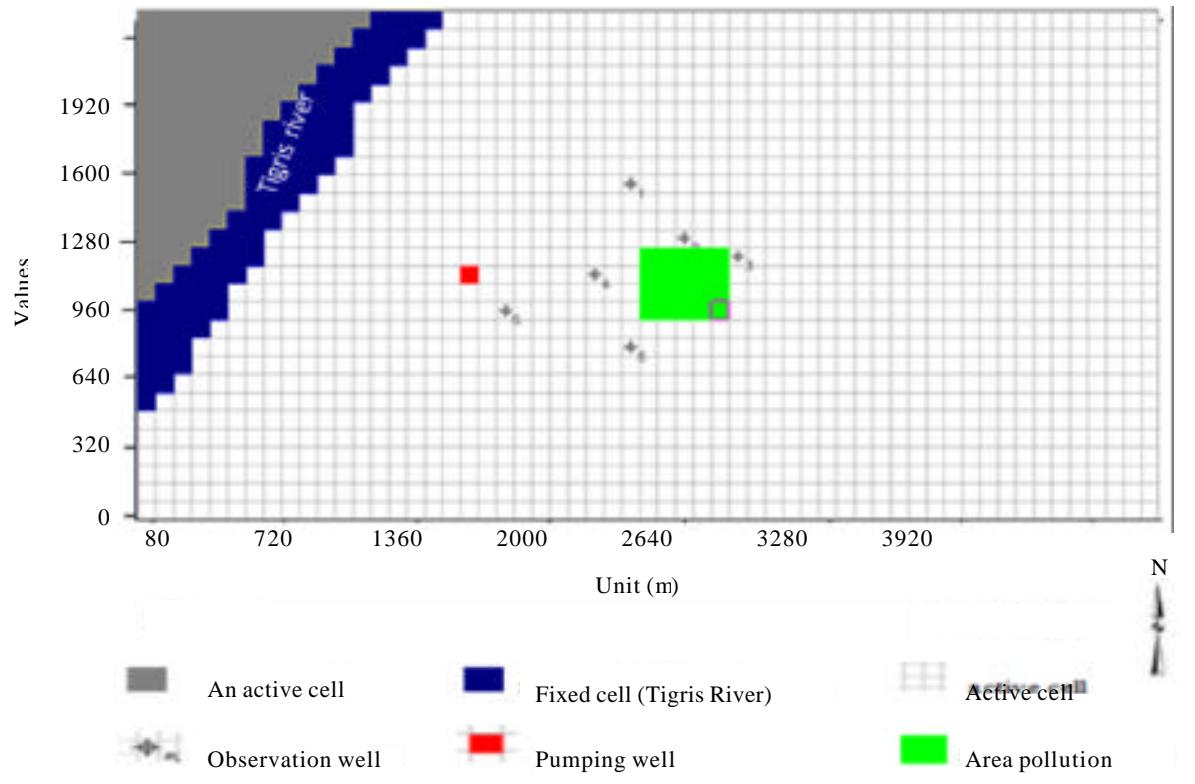

Fig. 2: Plane view of the model

The model domain and grids are the same for both the flow and transport model. The boundaries of flow model based on physical features and the hydraulic conditions, the cells that represent the Tigris River are defined as constant head boundary and the neighbored cells for the Tigris River from the North-West are considered inactive cells while other cells defined as variable head boundaries shown in Fig. 2. The value of water surface elevation for Tigris River is specified as a value of initial hydraulic head with 28.7 m.a.s.1 (Ali, 2012) while the boundaries of transport model are specified active cells and the initial concentration is assumed to equal to zero.

Model calibration: Model calibration is necessary to show that it simulates the groundwater behavior satisfactorily. Input parameters are adjusted until the model results agree with the field observations within a pre-established range of error in the calibration of the model (Kresic, 2006).

The steady-state model was calibrated by adjusting the hydraulic conductivity with the manual trial and error method. It showed relatively a good match between the calculated and observed heads for six observed wells which were chosen for this study as shown in Fig. 3.

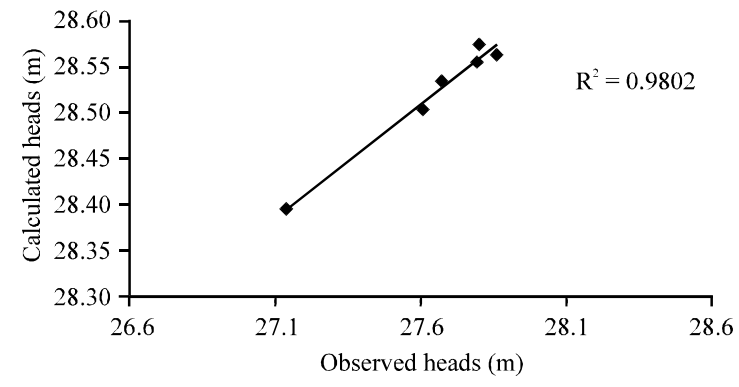

Fig. 3: Calculated and observed heads (m) of Al-Tuwaitha site

Contaminant Transport Model (MT3D): Hydrodynamic dispersion, advection and chemical reactions are processes that cause the transport of solute in porous media. The Method of Characteristics (MOC) is used to simulate the advection transport. The coefficient of molecular diffusion and dispersivity are used to describe the hydrodynamic dispersion for the solute in a porous medium (Zheng, 1990).

After a steady state run and the calibration of groundwater flow model, MODFLOW becomes ready to simulate transport model. The MT3D Model was linked 


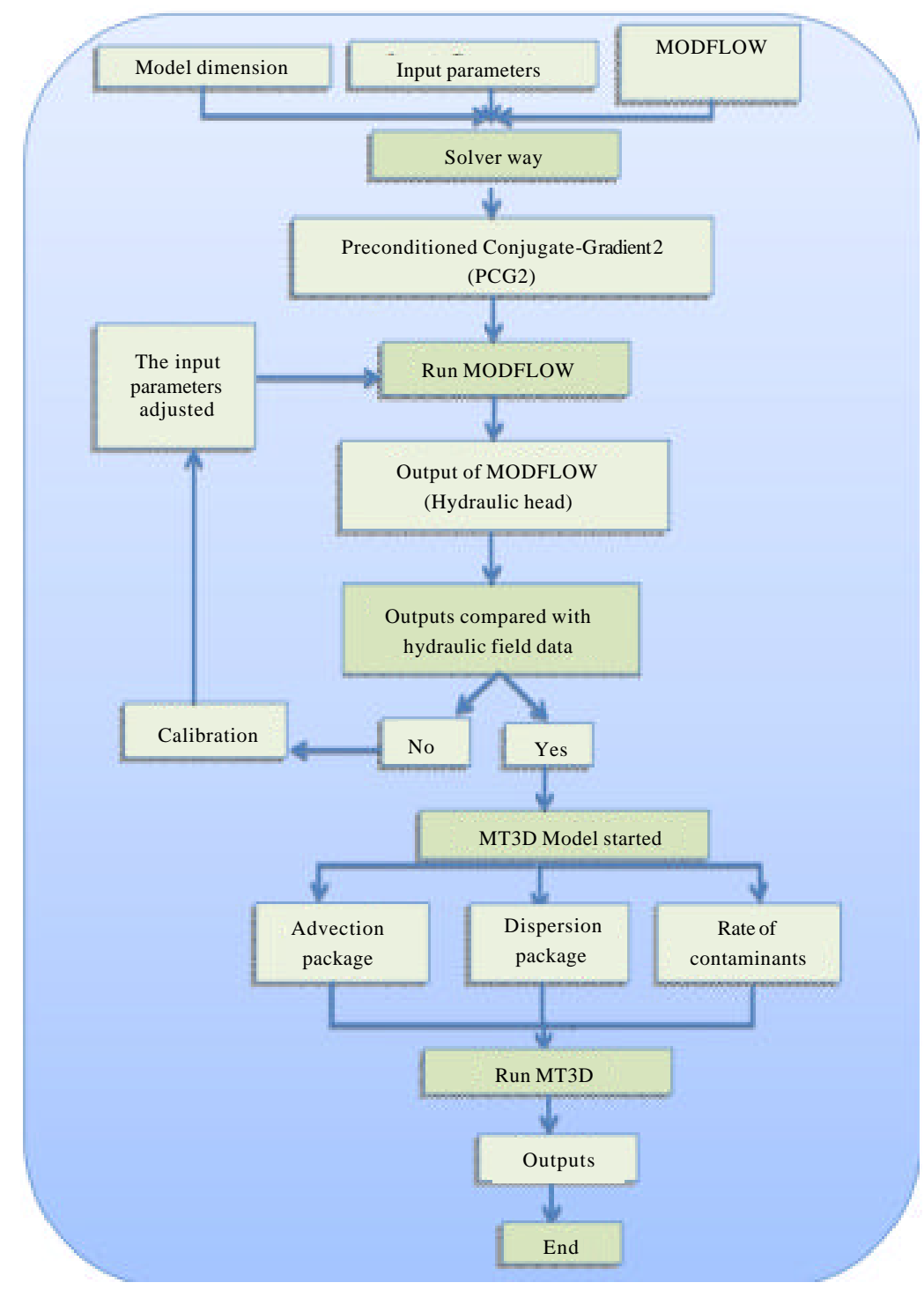

Fig. 4: Logical of the groundwater flow and contaminant transport models simulation

with MODFLOW Model. The MT3D Model was based on the results of groundwater flow model which was run with the average of the river water surface elevation. This study modeled the transport through advection and dispersion.

Steady state solute transport model: The model was run with Cs-137 concentrations of groundwater to prove and restrict the flow model. According to the studies conducted on Al-Tuwaitha area, it is shown that there is a presence of pollution in Al-Tuwaitha with radioactive materials which are considered a hazardous waste. So, it is important to keep track of the movement of pollutants in the aquifer. However, one site in this study is regarded as a possible contaminant as shown in Fig. 2. A Cs-137 concentration of $76.9 \mathrm{~Bq} / \mathrm{g}$, measured by Zaboon et al. (2014) using GIS technique was applied uniformly to the area contaminant. MT3D Model was run for 20 years for the imposition of that contamination which occurred in 2009. The steps which follow in performing the groundwater flow and contaminant transport models simulation shown in Fig. 4.

\section{RESULTS AND DISCUSSION}

The groundwater flow model was run at a steady-state after entering the data. Then the calibration model process achieved to study groundwater flow and transport model were started. In this study, the using of pumping well was proposed to collect groundwater 


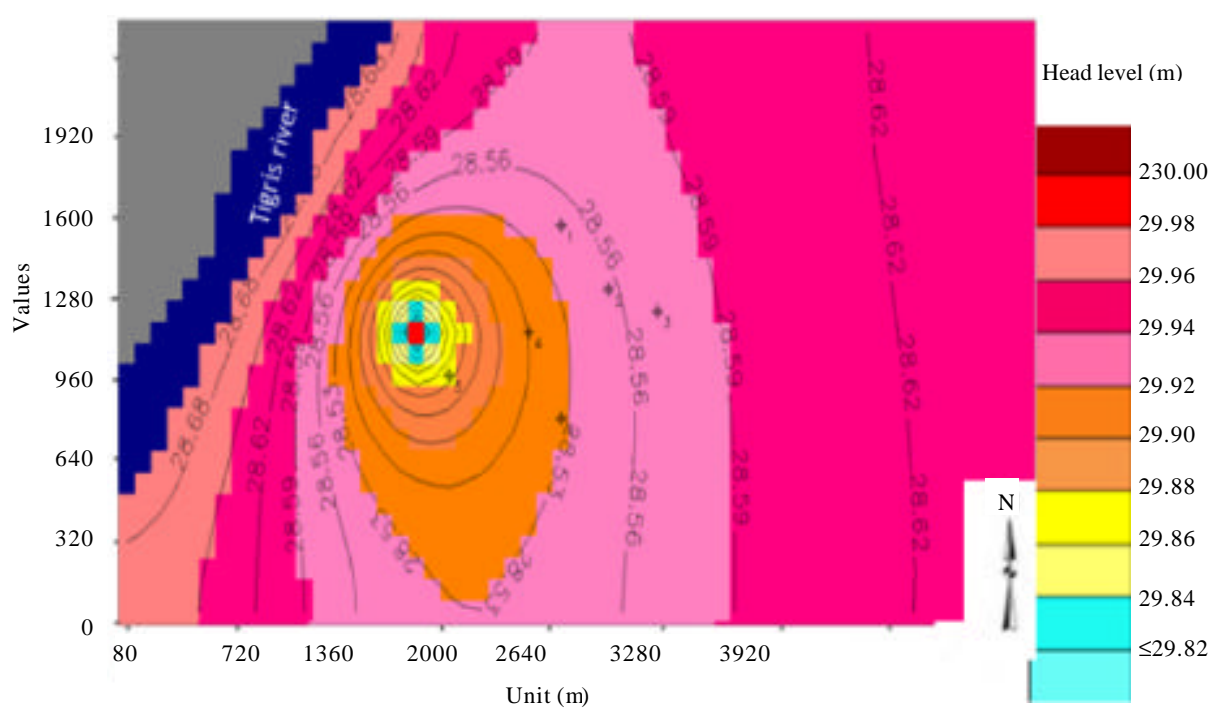

Fig. 5: The heads for the study area with used pumping well in the first layer

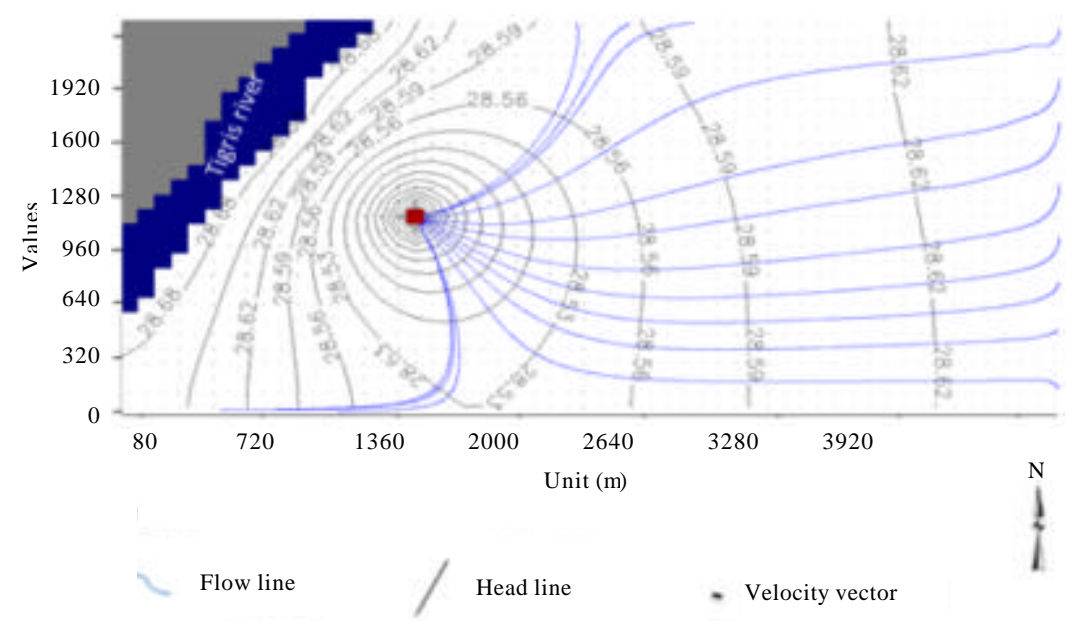

Fig. 6: Groundwater flow net direction in the first layer

contaminate flow and treat it prior to discharge to the Tigris River. Then, the transport model was run based on the results of groundwater flow model to estimate the distribution of contaminant concentration within the aquifer system.

The distribution equipotential lines of groundwater flow in the first layer are shown in Fig. 5. They have a high value at the Eastern part for the aquifer of $28.62 \mathrm{~m}$ while the least equipotential line has $28.26 \mathrm{~m}$ for area around the pumping well, therefore, the groundwater will move from the East part to West.

It has been noticed when the groundwater flow drawn by PMPATH Model that its movement is slow. Figure 6 shows the behavior of groundwater flow direction in aquifer system where water flow towards the pumping well, therefore, the effect of the pumping well is clearly, especially, in the area around the well. So, the movement of contaminant will be followed the groundwater movement and it will be toward the pumping well. The proposed pumping well operated to limit the movement of water contaminant toward the Tigris River and thereby reduces the movement of contamination deposited to aquifer from the surface for Al-Tuwaitha area near the Tigris River.

The transport Model MT3D was run under advection, dispersion conditions and the choice of the Cs concentration which is one of the radioactive pollutions in the soil of (Nuclear Research Center) Al-Tuwaitha area that has a long life. In this model, it was assumed that Cs-137 concentration considered from the standard 

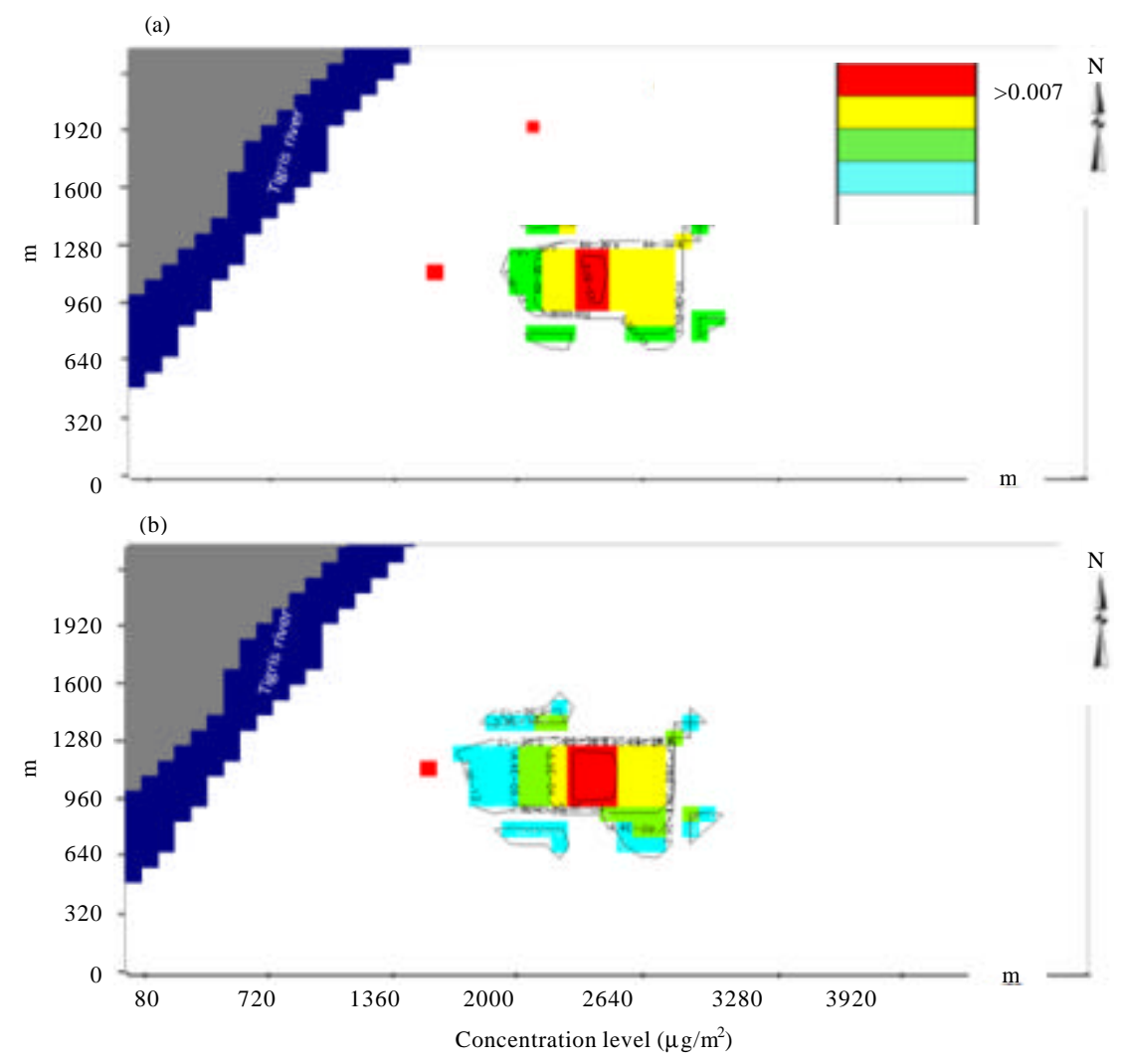

Fig. 7: Distribution of Cs-137 contaminate in the second layer after: a) 10 years and b) 20 years

limit of the radioactive pollution (Zaboon et al., 2013) and applied to polluted area as in Fig. 2. Cs-137 pollution model was simulated for 10 and 20 years to investigate the extent of migration of $\mathrm{Cs}-137$ concentration in the aquifer system. Cs-137 transport model simulation shows that it does not leak into the second and third layers after 1 year of simulation. Increasing simulation time leading to increase pollutant movement in vertical and horizontal direction toward the Tigris River as in Fig. 7 and 8a, b.

The results indicated that there was a slow migration of contamination which takes about 20 years to reach the well. Therefore, it can be considered that the suggested pumping well in this study was effective to reduce the contaminant migration towards the river. It was also observed that Cs-137 contaminant migration in horizontal direction is small because of flow groundwater seepage velocity where the advection is the main factor that controls the movement of contamination in the aquifer system. The dispersion has low influence because the longitudinal dispersion and diffusion coefficients are small for the aquifer and Cs-137 contaminant.

The model was calibrated by changing longitudinal dispersion and diffusion coefficients. A difference in the distribution of contaminant in the aquifer system was not observed but the highest change was observed through a change in the horizontal hydraulic conductivity of the layers. When the top layer is a sand layer, the spread of contamination will be very high and the possibility of its leakage to the Tigris River is higher. It specified $3 \mathrm{~m}$ as a value of the longitudinal dispersion coefficient and $2 \times 10^{-9}-5 \times 10^{-8} \mathrm{~m}^{2} / \mathrm{sec}$ as a value of the diffusion coefficient for layers of aquifer system while it specified $2 \times 10^{-6}$, $7 \times 10^{-5}$ and $3 \times 10^{-4} \mathrm{~m} / \mathrm{sec}$ as a value of horizontal hydraulic conductivity for the first, second and third layer, respectively. These values are used in this study.

The contamination model was operated based on the dispersion and advection factors and neglected the effect of the chemical reaction. Leakage of contaminant to the second and third layers does not occur during Cs-137 transport model simulation before 2 years because the first layer of loam clay has low permeability.

The rate of pollution increases whenever increases the amount of leaking material increases which may increase the amount of leaked material on the limit that has been used in the model as a result of the presence of polluting factors in the region. The increase of simulation time leads to increase the contaminated spread over a larger area and more depth. 

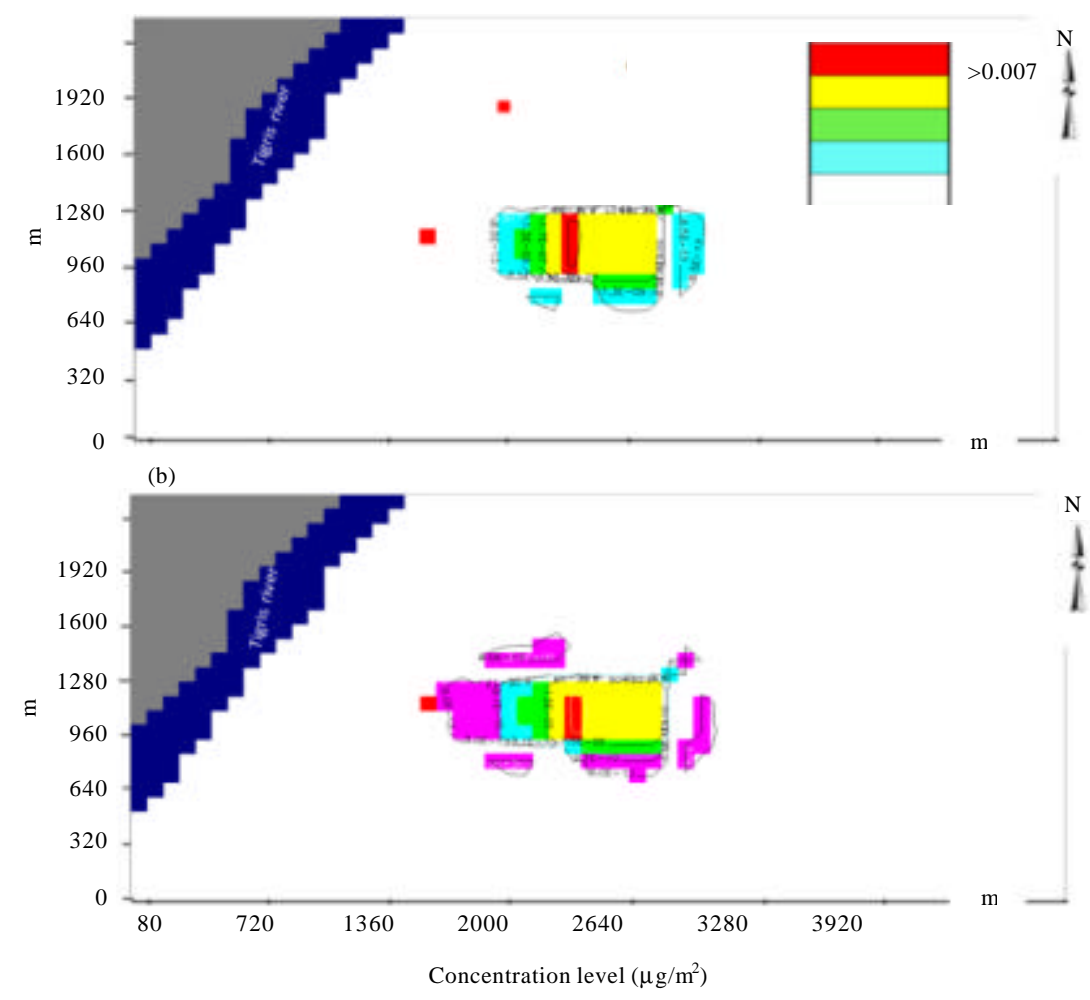

Fig. 8: Distribution of Cs-137 contaminate in the third layer after: a) 10 years and b) 20 year

According to this study, the movement of contaminants has been slow but it is the highest in the third layer, since, this layer is medium sand and has high permeability. Since, Al-Tuwaitha (Nuclear Research Center) is located near the Tigris River, therefore, the risk of contamination may increase and reach consumption sites. The half-life of cesium is relatively long and there must be a permanent observation to control the spread of contamination that may occur.

In general, the shape of the plume is oval but in this study it is closely a rectangular shape which follows the direction of ground water flow. It results from diffusion and longitudinal dispersion coefficients while the plume lateral spread is slight and depends on the transverse and vertical dispersion. The distance of the spread of Cs-137 was approximately $690 \mathrm{~m}$ after 20 years with the direction of groundwater movement toward the Tigris River. The use of pumping well was considered helpful in reducing the spread of contamination.

\section{CONCLUSION}

From the results obtained in this study, the following conclusions have been summarized below: the results show that there is a good agreement between the observed and the calculated heads by using MODFLOW. Groundwater flow direction was slow toward the Tigris River which influenced by soil type. The velocity of groundwater was $0.0015 \mathrm{~m} /$ day in the third layer and in the first and the second layers, the velocity were 0.00000977 $\mathrm{m} /$ day and $0.00036 \mathrm{~m} /$ day, respectively. The changing in the horizontal hydraulic conductivity of the first, second and third layer by $50 \%$ leads to increase the hydraulic heads by $5 \%$ for the third layer and $1 \%$ for the first and the second layer, respectively.

The increase of water elevation of the Tigris River leads to an increase in the hydraulic heads aquifer of groundwater level for the first and the second scenarios. The simulation results of the proposed pumping well lead to capture the flow lines of groundwater and change the movement direction. In addition lead to reduce the effect of the spread of the Cs-137 contaminant before reaching the river. The results of transport model show that the vertical migration of contaminant does not occur before 2 years of simulation time and increases with time. While the direction of the horizontal migration occurs after 10 years of simulation time with groundwater flow direction.

The Cs-137 concentration distribution shown in the aquifer for the study area during simulation MT3D Model 
that it is not affected by the variation in longitudinal dispersion and diffusion coefficient values but the variation in the distribution exists when the hydraulic conductivity values are changed into other limits.

\section{REFERENCES}

Al Obaidy, A.H.M., B.A. Mohammed and H.M. Al Sharaa, 2013. Radiological risk assessment for Al-Twuaitha nuclear site in Iraq. Intl. J. Energy Environ., 4: 409-414.

Al-Daffaie, S., 2014. Investigation and design of clay liner for radioactive waste landfill in Al-Tuwatha Site, Iraq. MSc Thesis, Department of Civil Engineering, University of Allahabad, Allahabad, India.

Ali, M., 2012. Hydrogeological environmental assessment of Baghdad Area, Baghdad. PhD Thesis, College of Science, University of Baghdad, Baghdad, Iraq.

Bucur, C., A. Popa, C. Arsene and M. Olteanu, 2000. Diffusion coefficients of critical radionuclides from radioactive waste in geological medium. Proceedings of the International Conference on Waste Management (WM'00), February 27-March 2, 2000, University of Arizona, Tucson, Arizona, pp: 1-12.

Chiang, W.H. and W. Kinzelbach, 1998. Processing modflow: A simulation system for modeling groundwater flow and pollution. MSc Thesis, Modflow Inc., Hamburg, Germany.

Copland, J.R. and J.R. Cochran, 2013. Groundwater monitoring program plan and conceptual site model for the Al-Tuwaitha nuclear research center in Iraq. Master Thesis, Sandia National Laboratories, Livermore, California, USA

Dmitri, B., 2014. Groundwater contamination following the chernobyl accident: Overview of monitoring data, assessment of radiological risks and analysis of remedial measures. Proceedings of the IAEA TM International Conference on Groundwater Contamination Following Fukushima Accident, September 8, 2014, International Atomic Energy Agency (IAEA), Vienna, Austria, pp: 1-22.

Gelhar, L.W., 1986. Stochastic subsurface hydrology from theory to applications. Water Resour. Res., 22: $135 \mathrm{~S}-145 \mathrm{~S}$.

Guzha, C., 2008. Integrating surface and sub surface flow models of different spatial and temporal scales using potential coupling interfaces. $\mathrm{PhD}$ Thesis, Utah State University, Logan, Utah.
Kresic, N., 2006. Hydrogeology and Groundwater Modeling. CRC Press, Taylor and Francis Group, New York.

LaForge, J.M., 1999. Radioactive cesium spill cooks Europe. Earth Island J., 14: 1-26.

Lee, J.O., W.J. Cho, K.W. Han and H.H. Park, 1990. A study on the migration characteristics of Cs-137 in a packed column. Nucl. Eng. Technol., 22: 20-28.

Pepper, I.L., C.P. Gerba and M.L. Brusseau, 2011. Environmental and Pollution Science. 2nd Edn., Academic Press, Cambridge, Massachusetts, USA., ISBN: 9780080494791 , Pages: 552.

Rasheed, N., 2013. The spatial distribution for the radiation pollution in lraq. J. Res. Diyala Hum., 57: 729-763.

Rushton, K.R., 2004. Groundwater Hydrology: Conceptual and Computational Models. John Wiley \& Sons, Hoboken, New Jersey, USA., ISBN:9780470871652, Pages: 430.

Shihab, R.M., 2014. Modeling of $137 \mathrm{Cs}$ and $60 \mathrm{Co}$ transport in calcareous soils by groundwater. J. Soil Sci. Environ. Manage., 5: 52-61.

Unterweger, M.P., D.D. Hoppes and F.J. Schima, 1992. New and revised half-life measurements results. Nucl. Instrum. Methods Phys. Res. Sect. A: Accel. Spectrom. Detectors Assoc. Equip., 312: 349-352.

Wiedemeier, T.H., H.S. Rifai, C.J. Newell and J.T. Wilson, 1999. Natural Attenuation of Fuels and Chlorinated Solvents in the Subsurface. John Wiley \& Sons, Hoboken, New Jersey, USA., ISBN:9780471197492, Pages: 617.

Zaboon, A.R.T., A.H.M.J. Al Obaidy and H.M. Al Sharaa, 2013. Radioactive doses contamination in $\mathrm{Al}$ Tuwaitha nuclear site, using GIS techniques. Eng. Technol. J., 31: 1612-1617.

Zaboon, A.T., A.M.J. Al Obaidy and H.M. Al Sharaa, 2014. Cobalt- 60 and cesium-137 soil contamination in Al Tuwaitha nuclear site, using GIS technique. Eng. Technol. J., 32: 3209-3215.

Zheng, C., 1990. A modular three-dimensional transport model for simulation of advection, dispersion and chemical reactions of contaminants in groundwater systems. Msc Thesis, United States Environmental Protection Agency, Washington, D.C., USA. 